\title{
FROM REPRODUCTION TO CREATIVITY AND THE AESTHETIC: TOWARDS AN ONTOLOGICAL APPROACH TO THE ASSESSMENT OF DEVISED PERFORMANCE
}

In Reproduction in Education, Society and Culture Pierre Bourdieu and Jean-Claude Passeron discuss the 'symbolic violence' of the education system. Systems of symbolization and meaning are imposed on groups or classes of people in a way that "renders them legitimate in the eyes of the beholder" (Bourdieu and Passeron, 1977, p.5). Pedagogic actions reproduce the values of the teacher, whether in a family or an institution, and are given legitimacy through the discourse of education. This reproduction of cultural values through education is what they call the 'cultural arbitrary' - it passes itself off as the natural order of things rather than as the arbitrary socio-historical construct that it is.

For Bourdieu and Passeron, those being taught are also in a system that focuses on being able to manipulate and reproduce culture rather than make it or seek to change it (in their terms 'symbolic mastery' is favoured over 'practical mastery'). In other words, the practical skills involved in making culture are given less weight than the study of it. This reproduces a method of education that suits the teacher, someone who has already mastered the academic discourse around the subject, rather than one that suits someone who seeks to creatively expand the subject. For those involved in teaching the arts this is reflected in the 'heritage' attitude of someone such as Peter Abbs, who emphasises in his book Living Powers the value of "inherited culture and a personal sense of cultural solidarity, of belonging to an 
historical past which gives depth and meaning to the present" (Abbs, 1987, p.3, original emphasis).

As a teacher and practitioner who has taught devised performance at both school and university level, and who would describe myself as someone keen to promote a progressive curriculum where students engage with the world around them, what are the implications of this for my teaching practice? In particular, how might I deal with my own "cultural arbitrary" whilst assessing practical work when students create moments that have a sense of something that I find difficult to understand or measure? These are the moments that I most treasure as a teacher, the moments when I know the student may have found something really exciting, and yet they are the very moments when my assessment criteria seem redundant. How can I theorise an approach to assessing new work which does not encourage students to reproduce, but rather encourages them to innovate?

In this article I would like to suggest a three pronged ontological approach to assessment that seeks to avoid the dangers of reproduction, and which instead values students' production (or, to use a term perhaps more appropriate to art, creation). Firstly I would like to suggest an embracing of the ambiguities in moments, such as those described above, which allow for the shifting of conceptual boundaries. Secondly, I would like to suggest that in such moments is created a social interaction between artwork/student and spectator/assessor that is indicative of both the arts generally and live performance specifically. Finally, I suggest that we require students to explore the frontiers of what can be created - explored, shown and understood - through performance. 


\section{ASSESSMENT}

Assessment is, of course, a broad church. It can be about asking questions of the work. It can be about getting students to peer or self-assess. The student can determine the focus of the assessment. It can be qualitative rather than quantitative. For the purposes of this article, I am focusing on quantitative summative assessment, or what Harlen has called "'checking up' models that are generally carried out through providing tests or tasks specially devised for the purpose of recording performance at a particular time" (Harlen, 1994, p.280). These are arguably the most frequently discussed form of assessment, perhaps because the closed nature of assigning a quantifiable number or letter to any piece of work can never fully reflect its form or content. It is also the form of assessment that is frequently of most concern to students and teachers in the contemporary context because it is the one that directly impacts upon students' results and institutions' ratings.

There are of course many people who believe that it is unnecessary to assess in such a way at all. However, putting aside the question of whether such summative assessment is desirable or necessary, when it is unavoidable - as it is for most people in education at present - there is an understandable concern, perhaps particularly in the "insecure territory" (Paul Bridges, cited in Dixon, 2000) of the arts, to ensure clarity and parity in the system through specific criteria, intended learning outcomes and clear mark schemes. Such an approach has arguably often meant that what is sought from students is easily quantifiable. In Feeling and Reason in the Arts David Best outlines the example of Rembrandt's paintings: "whether or not [the 
viewer] dislikes them, if he is unable to recognise any artistic merit, even of technique, for instance, that would be a good ground for saying, analogously, that he simply has no understanding of what constitutes good painting" (Best, 1985, p.40, original emphasis). In this example the technical skill evident enables assessment to become easier for the assessor and the "territory" becomes more "secure". In devised performance such an approach might be seen in an obsession with technical skill, with the ability to use stimuli, the ability to explore a topic in depth criteria that are perhaps easier to quantify because they are already established as facets of the discipline. Yet such an approach in isolation could lead back to a reproductive Abbsian concept of heritage art where the past defines the values of the present.

Prescriptive assessment criteria may seem to sit particularly awkwardly with creative work, which is inevitably about outcomes that cannot be predicted in advance and are often innovative. Perhaps it is this that leads to the fear of assessment of many involved in arts education. For example, Paul Kleiman (2007) has given the advice, in his "Rough Guide to Assessment", to "assess as little as possible, but as much as necessary". Steve Dixon (2000) has stated that teachers of Theatre Studies are "using an inappropriately rational, objective, quasi-scientific model to assess a largely irrational, spontaneous and subjective art". He cites Paul Bridges' research into discipline related marking behaviour that observed that teachers of arts and the humanities in British universities "rarely mark outside the 40 - 70\% range", and Bridges' suggestion that this is due to the perception that "the extremities of the percentage scale are insecure territory for assessors of qualitative subject matter". 
(These contrast, he says, with science subjects such as mathematics and computing where the whole percentile range is used $)^{1}$.

However, I want to suggest that it is difficult, but not impossible, to assess creative work against marking criteria that are not reproductive. In Feeling and Reason in the Arts David Best suggests that whilst arts cannot be measured in the same way that science can, this does not eliminate the possibility of objective assessment where the reasons for a judgement are made clear. There is a distinction, he claims, between non-rational personal preferences (p.37) and opinions made with reference to value-judgements (p.36) and criteria. There is no timeless truth about what makes good art that is universal across cultures. Different eras and cultures conceptualise and evaluate art differently, but this does not mean that it is not possible to substantiate one's assessment with reasons, or criteria.

I want to further suggest that these criteria need not bow to the conventional to ensure clarity and parity. Bourdieu and Passeron's concept of the 'cultural arbitrary' is mirrored in Jacques Rancière's comments that both "art and politics are contingent notions" (Rancière, 2004, p.51) and that "politics and art, like forms of knowledge, construct 'fictions'” (p.39), or ways of seeing the world rather than timeless, transcendental truths. But if one accepts Rancière's view that not only art but also politics is an historical, non-natural phenomenon, Foucault's revelation that discourses such as sexuality, law and madness are also historical constructions, or indeed Raymond Williams' linking of the British education system to historical phenomena rather than a trans-historical conception of educational value (Williams, 1961, pp.145-176), one sees that the discourse of the arts - including devised 
performance - are not alone in their historical variation or, indeed, their ontological instability. So if not only the arts but all subjects and discourses shift over time and are unstable, an assessor need not fear the difficulty of a student's shifting of existing paradigms, but can rather see this challenge as an inevitable possibility of working in any field and embrace it. Indeed, the extent to which the work is offering original insights into the discipline and moving it forward could be an assessment objective. What value-judgements and criteria are being used for assessment in devised performance, the arts or indeed any subject are therefore up for negotiation, and are important: assessment institutions' decisions about what value judgements and criteria are used will arguably influence what is taught, particularly in a culture such as the contemporary British one which is so keen to judge on exam results.

\section{RANCIĖRE, WILLIAMS AND THE AESTHETIC}

I want to start to explore what the arts, and devised performance specifically, might posit as their approach to assessment by offering an ontological view of the arts through the theories of Rancière and Raymond Williams. I will suggest a connection between these two writers from very different contexts - a connection that I would suggest can offer a way of analysing aesthetics and the function of art. I will argue that both critics agree that there is both an inherent connection between art and society, and that art is vitally separate from society.

Rancière distinguishes between three 'regimes' of art: the 'ethical regime of images', the 'poetic' regime, and the 'aesthetic' regime (Rancière, 2004, pp.20-22). For Rancière the ruling body (or what he elsewhere calls the 'police') (p.2) determines the ethical regime: the images "provide the spectators, both children and adult 
citizens, with a certain education and fit in with the distribution of the city's occupations" (p.21). The poetic regime is a version of mimesis that is still rooted in the ethical regime but then adopts a poetic relation to it. The aesthetic regime, however,

strictly identifies art in the singular and frees it from any specific rule, from any hierarchy of the arts, subject matter, and genres. Yet it does so by destroying the mimetic barrier that distinguished ways of doing and making affiliated with art from other ways of doing and making, a barrier that separated its rules from the order of social occupations. The aesthetic regime asserts the absolute singularity of art and at the same time destroys any pragmatic criterion for isolating this singularity (p.23).

For Rancière, the aesthetic's 'singularity' does not separate it from a social function, since via the avant-garde it can invent "sensible forms and material structures for a life to come" (p.29), moving beyond the technique of the representative and the 'sensible' nature of the mimetic into territory beyond mainstream discourse, territory that cannot easily be talked about within language. The aesthetic as defined by Rancière allows for a celebration of aspects of art that are not reducible, not quantifiable, and not able to be mapped on to something else.

At first glance, Raymond Williams' essay 'The Creative Mind' seems to see art in different terms. For Williams art does not exist in a vacuum but as part of a social context. He states that "communication is at the crux of art" (Williams, 1961, p.46) and that "nobody can see (not understand, but see) the artist's actual work unless he 
and the artist can come to share the complex details and means of a learned communication system" (p.41). He would therefore seem to see a shared understanding as being essential between art and life, between artist and audience, with meaning passing directly between the two in contrast to the difficulty of "isolating" the "absolute singularity of art" suggested by Rancière. Moreover, in stating that when the concept of art as 'creative' was "extended to a contrast between art and life, between art and ordinary experience, the consequences were very damaging" (p.53), he seems to be requesting that art holds up a mirror, however much it may be a distorted one, to society. This would appear to be an attitude far removed from both the avant-garde and the 'singularity' that Rancière is talking about.

However, on closer inspection one can find connections between their writings. To take Williams first, he is clear that whilst art is linked to experience, it is not limited to it: "The special nature of the artist's work is his use of a learned skill in a particular kind of transmission of experience" (p.42, my emphasis). The arts function as "developments from general communication" (p.40, my emphasis) as the artist channels responses to contemporary experience into artistic media with a "substantial number of the offered meanings [becoming...] composed into new common meanings, though after initial disturbance and with a time-lag that again makes us conscious of the fact of change" (p.49).

Rancière is actually articulating a similar view of the artist's relation to society in his distinction between the aesthetic and the ethical/poetic, since he indicates the aesthetic's radical difference from everyday life as being its ability to comment on it. 
His notion of the aesthetic offers new ways of imagining, of work that understands its social necessity but which defines its own rules, of work at the vanguard of creation. This would not be possible in the ethical or poetic regimes of art that are conceptually limited by contemporary understanding, doomed to remain in a reproduction of it - albeit in an altered, artistic form. The aesthetic, on the other hand, is paradoxically both inside and outside the existing order. It lies beyond everyday existence, but this separation from the everyday is what gives it its social charge.

For both Rancière and Williams, then, social relations are at the centre of art. And yet for neither is this about subsuming art to a purely social function. To quote Claire Bishop, "for Rancière the aesthetic doesn't need to be sacrificed at the altar of social change, as it already contains this ameliorative promise" (Bishop, 2006, p.182). Rather, it is about recognising art as a social function in itself that creates its own parameters. Art is not something that only happens in arts centres or in ways sanctioned by the Arts Council. Indeed, Clifford Geertz (1983) argues that Western societies are unique in positing a difference between art and the wider social context, and that in other cultures it is part of everyday life. Human beings create, as part of life, moments that can be considered artistic. We can create plates of food that have great visual beauty (and isn't the taste a kind of aesthetic experience too?) When describing Brecht's street accident the witness can reveal an unerring awareness of the driver's arrogance. The song sung during work can bring tears to a listener's eye. All of these contain an element beyond their immediate utilitarian function, of something that lies beyond the everyday. They do not, either, fit with a consciously poetic reflection of the everyday. Such elements do fit with Rancière's definition of a 
"destr[uction of] the mimetic barrier that distinguished ways of doing and making affiliated with art from other ways of doing and making". They do more than just reproduce the expectation of such a moment, producing rather a moment that is difficult to comprehend in any realm other than the aesthetic realm of art.

This conception of art sees as false any division between the notion of art as either being "removed from the scope of common and community life" (John Dewey, 1934, p.6 cited in Greene, 1995, p.146), as an elitist activity derided by Benjamin as "auratic" art (Benjamin, 1970), and art on the other hand as needing to be subsumed to a social function. Rather, it suggests that because art "breaks open a dimension inaccessible to other experience, a dimension in which human beings, nature and things no longer stand under the law of the established reality principle"(Marcuse, 1977, p.72, cited in Greene, 1995, p.138), new possibilities to life can be imagined. As Brecht suggested, a distance between art and reality might be crucial if art is to retain a political edge (Brecht, 1974, p.139).

As someone seeking to argue for a non-reproductive arts education I want to suggest that this notion of the aesthetic must become a vital facet of its assessment. It may seem tautological to suggest that the aesthetic be embedded in arts education. But for educators such an approach poses some significant challenges to current thinking. For totally logical and well intentioned reasons the arts' unique ability to stand outside society is increasingly eschewed in favour of requiring it to fulfil social functions. For example, Government friendly bodies have recently harnessed the term 'creativity', traditionally seen as belonging in the domain of the arts, as a solution to an education system that does not encourage individual thought 
(even though it is premised on individual achievement). ${ }^{2}$ And Arts Council funding requirements, alongside well-intentioned work in applied theatre contexts, increasingly require artists to consider the social impact of their work. My aim is not to criticise such approaches per se, but to suggest that there may also be a value in work that stands beyond such aims and allows for Bishop's "ameliorative promise" of the aesthetic. Indeed, there may be a deeper impact from work that does not subordinate itself to a solely social purpose. As John Tusa has said, "the arts probably are instruments for social improvement, agents for social change, for social equality, or for community harmony. Yet [...] these demands [...] set a list of challenges which are not intrinsic to the arts, are distant from their true nature and all of which could be antithetical to their basic functions and purposes" (quoted in Belfiore and Bennett, 2008, p.8).

This opens up some interesting possibilities for the teaching and assessment of the arts. Perhaps assessors can reconfigure a concept of the social that is embedded in aesthetics. Perhaps assessors can value aesthetic and creative processes that by definition do not evoke easily comprehensible responses, existing as they do in the ephemeral world of the aesthetic. But how might performance specifically engage with these issues?

\section{PERFORMANCE AND ASSESSMENT}

Metaphor works to secure a vertical hierarchy of value and is reproductive; it works by erasing dissimilarity and negating difference; it turns two into one. Metonymy is additive and associative; it works to secure a horizontal axis of contiguity and displacement (Phelan, 1993, p.150, my emphasis). 
Richard Schechner has suggested that "just about anything can be studied "as" performance" (Schechner, 2002, p.30): that any event can be studied as a specific event, a specific iteration. For example, the "same" performance performed in one context to a black audience or in another to a white audience may mean totally different things. In this sense rather than conceptualising performance as being "about" real life, a metaphor removed from reality which comments on reality, each performance can be seen as a unique entity, metonymic in its combination of disparate elements. For Peggy Phelan performance therefore avoids reproduction, it is "representation without reproduction" (Phelan, 1993, p.146). Echoing Rancière's aesthetic regime which "asserts the absolute singularity of art", this conception sees each performance existing in unique time and space, irreducibly itself, not merely standing in for something else - even at its most conventionally representational.

However, it is "representation", intrinsically linked to reality. Citing Victor Turner, Marvin Carlson discusses "not so much the "set-apartness of performance but its "inbetweenness", its function as transition between two states of more settled or more conventional cultural activity" (Carlson, 2004, p.16). Not only does performance often blur the boundaries between truth and illusion, but there is also an inherent duality in the simultaneous reality of the live performative event alongside its existence as "restored" behaviour (Schechner, 2002, p.22). Carlson similarly states that "objects and actions in performance are neither totally "real" nor totally "illusory," but share aspects of each" (Carlson, 2004, p.49). Phelan describes a similar ambiguity by stating "each performance registers how much we want to believe what we know we see is not all we really have, all we really are. That negation reveals the 
generative possibility of the "not all" that keeps us hoping" (Phelan, 1993, p.178). In performance then, there may be an ontological ambiguity about what one is watching that can be embraced as part of a non-reproductive logic that sees performance as a politically significant creation of new possibilities.

The co-existence of a live performer with an audience in performance creates a social relation between artist and community specific to its unique utterance. For Phelan this suggests an ethical significance to performance: she states, "The ethical is fundamentally related to live art because both are arenas for the unpredictable force of the social event" (Phelan, 2004, p.575). Philip Auslander has criticised Phelan's ontological approach as being inherently oppositional to an historical one (Auslander, 1999, p.51), but I would suggest that her approach should be seen differently. Rather, an ontological approach to performance might insist on historical, social and political contextualisation as part of a project of interrogating the specificity of each performance.

These conceptions of performance fit with the ontology of the arts proposed above: that of being a vehicle for the creation of new possibilities, of embracing the ambiguity of the aesthetic, and of containing an inevitable social significance. These three notions reflect the three pronged assessment model I outlined at the beginning of this article, and also come together in Maxine Greene's suggestion that "reality is multiple perspectives and that the construction of it is never complete, there is always more" (Greene, 1995, pp.130-1). Although Greene's comment is about the arts generally, it could apply particularly well to performance. Performance realises 
a human capacity to construct new realities in real time and space, a construction that is by definition creative rather than reproductive.

I am going to use the work of the company Goat Island, now sadly no more, to suggest some ways in which this conception of performance might be realised. For this company devised performance is not seen in isolation but as part of a wider social context. Yet this social engagement is made possible through a conceptualisation of their work which I would argue is similar to Rancière's aesthetic, which insists on their practice existing outside the economy of everyday life in order to be able to create "small acts of repair" (the title of a book about their work) which could function as possibilities for the future.

The company's work starts from a seed of enquiry, in the case of It's an Earthquake in My Heart, with nothing other than

an idea to study cloud formations, which evolved into ideas about paths and chases, which evolved into research into cars and traffic patterns and then into hand gestures and the circulatory system. Like a system of roots underground the sources of material fan out in several directions with many forks and diversions along the way. (Karen Christopher, quoted in Bottoms and Goulish (eds.), 2007, p.13)

Steve Bottoms describes this "forking out" as like Deleuze and Guattari's notion of the rhizome, which makes lateral and subjective, rather than linear and logical, connections. In these connections appropriated fragments are "treated less as 
fragments (deconstructed originals) than as constituent components in a new structure, a new ecology of interconnected points" (Bottoms and Goulish (eds.), 2007, p.65). The new structure created is made up of many different elements. In a Goat Island show one might find abstract movements originating from one of these fragments. These movements might present themselves slowed down, or speeded up. The body thus takes on unfamiliar physicalities and ways of moving that, whilst reminiscent of and partly inspired by dance, are a long way from its conventions. One performer might speak text into microphones whilst another undertakes an action repetitively and obsessively. The mood is hypnotic and can sometimes feel frustrating. But in the watching of the work time feels different and in the watching of the work I find that I free associate, finding rhizomatic connections between different moments and different elements. There is a sense of an artificial world being created from the fragments of reality in front of the spectator's eyes, and yet this world makes me reflect on my own. This is reflected in Mark Jeffery's comment (a performer in the company) that "artifice gives us another way of looking, another way of connecting to and working with both the fake and the real" (quoted in Bottoms and Goulish (eds.), 2007, p.46). Via Phelan, one might map this conception of artifice onto metonymy: an artifice that could function as the creation of a new reality.

In this new reality it may be difficult to find the logic, but in the search to make sense of the juxtapositions the spectator is liberated to see things anew, to have a new experience in a manner similar to Kate Love's comment that

When I've said "I've had an experience" $[\ldots]$ I realise that I have probably used the word because I want to register the precise feeling that that which I 
have just lived through was something like an approach to the world which I both recognised, and yet didn't quite recognise, a space which was both in language but yet not quite in language, at the limit of language but unequivocally not beyond. (Love, 2005, p.169)

Such an experience is for Love a "negotiation with language", and if one accepts the poststructuralist notion that language "is the place where actual and possible forms of social organisation and their likely social and political consequences are defined and contested" (Weedon, 1987, p.21), one can see this negotiation as a political act, an act that functions as a creation of new possible meanings. This negotiation can also be related to the Raymond Williams notion above of the artist creating a new language that is put into negotiation with her society. In its exploration of meaning and creation of new worlds, such work may have more political efficacy than a performance that attempts to confront an "issue" head on but fails to offer any imaginative perspective on it.

This creation of imaginative perspectives is not only evident in Goat Island's performance practice but also in their process. Process was immensely important to them - their creation of "schoolbooks" and the 64 pages of Bottoms and Goulish's book on process reflect this. When making work, they sought to create new ways of working that challenged conventional notions of performance as commodity. Failure is embraced as a necessary part of an unpredictable creative process: as Matthew Goulish has put it, "We seek truth, we encounter error. It is obvious, like truth" (Goulish, 2004, p.261). Comparing the "economically oriented model" of traditional theatre with Goat Island's practice where they "are out to discover something we 
can't imagine at the point at which we start", Karen Christopher uses as a metaphor the "rigid controlling hand" of mono-crops with the complexity of attention needed in an eco-system to "creatures and minerals and soil and air and water" (p.119).

In taking our time, we have created an abundance of material that feeds the development process [...] Eventually the work begins to make itself; the accumulation of material begins to suggest certain directions. This method is not at all efficient in an economic sense, and yet no part of it is superfluous. (p.120)

Such a view could be seen as contrasting the reproductive logic of mono-crops with the creative logic of ecology. This creative logic does not posit creation as an end in itself, but rather accepts its failures as part of a productive process which allows it to redefine its goals. It sees itself as seeping into all areas of life. It creates microcosms of effective praxis. For example, a feature of the Goat Island workshops I have participated in make a virtue of letting go of one's own ideas and accepting those of others. This views art making as an act of generosity and acceptance that creates a different relationship to others than that prevalent in the pursuance of selfrealisation within contemporary capitalism. The community works together to reach a common goal. To quote Mark Jeffery, "this idea of ownership becomes a wider participation, and one of interaction, circulation, and creativity" (Mark Jeffery, quoted in Bottoms and Goulish (eds.), 2007, p.219).

It is notable that Goat Island, a company known for making complex, abstract and what was often perceived as "difficult" work, has such concern for its social impact. I 
would suggest that this reflects the possibility that their "small acts of repair" are the enactment of Rancière's "ameliorative promise" of the aesthetic; that through conceiving performance specifically (and the arts generally) as existing both within and beyond the everyday their work attains a vital social charge.

\section{ASSESSMENT PRACTICES}

I have attempted to draw three strands through this article in the formulation of a creative, non-reproductive approach to assessment: the inherently unstable nature of the aesthetic, the arts and performance as a place for creating new possibilities, and the social engagement implicit in both the above. I would like to conclude by considering what this conception of performance practice and process might mean for the quantitative measurement of students. In doing so I am keen to recognise each performative encounter as existing in the aesthetic regime, as being ephemeral, unique, and as therefore only able to be analysed in its specific context. This approach thus attempts to avoid hardening into a reproductive logic by shifting from the cultural arbitrary of the past to an exploration of the specifics of the present and the creation of possibilities for the future. This approach sees the aesthetics of performance, via Rancière's aesthetic, as a social function in itself.

Firstly, I would argue that students will be more imaginative if we measure their ability to see what already exists with fresh eyes, their ability to create work that puts reality under an imaginative microscope by taking it apart and reconfiguring it. We can measure their work by its ability to look at a known situation in an unknown way, recontextualising it and enabling new perspectives on it to be created. 
Secondly, we can measure their engagement with the limitations of representation, asking them to explore beyond what is already known or imaginable. For example, in their Schoolbook 2 Goat Island set students the exercise of coming up with "impossible tasks" which are then turned into performative moments. For example, "Fly. Draw the world (actual size). Dissolve my body" (Goat Island, 2000, pp.12-13). The student is encouraged to think about the limits of representation and how to move beyond it. It is not possible to measure the success of a student's response to this task by comparing their work with any preordained outcome. Rather, the student's ability to use skills such as imagination and creativity, and their attempts to understand the world and to explore the frontiers of representation, are measured and valued.

And finally I would suggest that we could measure social interaction, recognising that students' devising practice will have ramifications both within and beyond the rehearsal room. We can request that they explore bravely, accepting the inevitable failures along the way as being an essential part of any truly explorative process. We can see such failure as an opening to new understanding. We can require students to make work that has a sense of its own ecology - seeing an artistic process as an interaction, albeit a small one, with the world.

I would like to conclude by proposing Goat Island's comments on criticism as pertinent advice to assessors endeavouring to quantify these creative processes:

If we think of critical as negative [...] then problems become the object of our creative mind masquerading as a critical mind. We then start to see problems 
everywhere... For now we will try an experiment. We will engage the critical mind to observe the moments in the work we are looking at that seem to us the most exceptional and inspiring - the miraculous moments. Maybe this approach will allow us to keep the creative mind deliberately engaged as we engage the critical mind. Maybe we will start to see miraculous moments everywhere (Matthew Goulish, quoted in Bottoms and Goulish (eds.), 2007, pp.210-11)

Asking assessment criteria - and therefore students and assessors - to focus on finding such miraculous moments can perhaps enable a shift from a fear of assessment as critical and reproductive towards seeing it as a quest for new possibilities, as a creative engagement with moving both artistic and social practice forward. 


\section{References}

Abbs, P (Ed.) (1987) Living powers: the arts in education (Lewes/Philadelphia:

Falmer)

Auslander, P (1999) Liveness: performance in a mediatized culture (London/New York: Routledge)

Belfiore, E and Bennett, O (2008) The social impact of the arts (Basingstoke: Palgrave Macmillan)

Benjamin, W (1970) 'The work of art in the age of mechanical reproduction', Illuminations (Harry Zohn, Trans.) (London: Cape)

Best, D (1985) Feeling and reason in the arts (London: Allen and Unwin)

Bishop, C (2006) 'The social turn: collaboration and its discontents', Artforum (February), 178-183

Bottoms, S and Goulish, M (eds.) (2007) Small acts of repair: performance, ecology and Goat Island (Abingdon/New York: Routledge)

Bourdieu, P and Passeron, J-C. (1977) Reproduction in education, society and culture (Richard Nice, Trans.) (London: Sage)

Brecht, B (1974) Brecht on theatre: the development of an aesthetic (John Willett, Trans.) (London: Eyre Methuen)

Carlson, M (2004) Performance: a critical introduction (Abingdon/New York: Routledge)

Deleuze, G and Guattari, F (1987) A thousand plateaus: capitalism and schizophrenia (Brian Massumi, Trans.) (Minneapolis: University Press)

Dewey, J (1934) Art as experience (New York: Minton, Balch)

Dixon, S (2000) 'Assessing the performer', palatine.ac.ukeventsviewdoc57.pdf

Geertz, C (1983) 'Art as a cultural system', Local knowledge (London: Fontana)

Goat Island (2000) Schoolbook 2 (Chicago: Goat Island)

Goulish, M (2004) 'Peculiar detonation: the incomplete history and impermanent manifesto of The Institute of Failure', in Helmer, J and Malzacher, M (eds.), Not even a game anymore: the theatre of Forced Entertainment (Berlin: Alexander Verlag)

Greene, M (1995) Releasing the imagination (San Francisco: Jossey-Bass)

Harlen, W et al (1994) 'Assessment and the improvement of education' in Moon, B and Shelton Mayes, A (eds.), Teaching and learning in the secondary school (London/New York: Routledge) 
Kleiman, P (2007) 'Starting out: assessment', paper presented at Starting Out workshop, Lancaster, organised by Palatine, 20th October 2007

Love, K (2005) 'The experience of art as a living through of language' in Butt, G (Ed.) After criticism: new responses to art and performance (Oxford: Blackwell)

Marcuse, $\mathrm{H}$ (1977) The aesthetic dimension (Boston: Beacon)

NACCCE (National Advisory Committee on Creative And Cultural Education) (1999) All our futures: creativity, culture \& education (London: DfEE Publications)

Phelan, P (1993) Unmarked: the politics of performance (London/New York: Routledge)

Phelan, P (2004) 'Marina Abramovic: witnessing shadows', Theatre journal 56:4 (December), 569-577

Rancière, J (2004) The politics of aesthetics: the distribution of the sensible (Gabriel Rockhill, Trans.) (London/New York: Continuum)

Schechner, R (2002) Performance studies: an introduction (Abingdon/New York: Routledge)

Seltzer, K and Bentley, T (1999) The creative age (London: DEMOS) available at http://demos.co.uk/publications/creativeage

Weedon, C (1987) Feminist practice and poststructuralist theory (Oxford: Blackwell) Williams, R (1961) The long revolution (Harmondsworth: Penguin)

\footnotetext{
${ }^{1}$ Paul Bridges et al (1999), 'Discipline-related marking behaviour using percentages: a potential cause of inequity in assessment', Assessment \& evaluation in higher education 24 (3), pp. 285 - 300 , quoted in Dixon (2000)

${ }^{2}$ See, for example, Seltzer and Bentley and NACCCE.
} 